\title{
Trauma to the Male External Genitalia: Epidemiology, Diagnosis and Therapeutic Aspects at Yalgado Ouedraogo Teaching Hospital of Ouagadougou
}

\author{
Barnabé Zango1, Fasnéwindé A. Kabore', Abdoul Karim Pare ${ }^{2 *}$, Brahima Kirakoya1, \\ Clôtaire Alexis Marie Kiemdiba Donega Yameogo'1, Adama Ouattara', Cyprien Zare ${ }^{3}$ \\ ${ }^{1}$ Department of Urology, Yalgado Ouedraogo Teaching Hospital, Ouagadougou, Burkina Faso \\ ${ }^{2}$ Department of Urology, Sanon Souro Teaching Hospital, Bobo Dioulasso, Burkina Faso \\ ${ }^{3}$ Department of General Surgery, Sanon Souro Teaching Hospital, Bobo Dioulasso, Burkina Faso \\ Email: boupare@yahoo.fr
}

Received 17 May 2015; accepted 16 July 2015; published 20 July 2015

Copyright (C) 2015 by authors and Scientific Research Publishing Inc.

This work is licensed under the Creative Commons Attribution International License (CC BY).

http://creativecommons.org/licenses/by/4.0/

(c) (i) Open Access

\begin{abstract}
Objective: To describe the epidemiology, diagnosis and therapeutic outcomes of trauma to the external genitalia trauma. Materials and Methods: This is a retrospective descriptive study over a period of six and a half years from January $1^{\text {st }}, 2006$ to June $30^{\text {th }}, 2012$. About 42 cases of trauma to the male external genitalia were received at the emergency department of General surgery and Urology of Yalgado Ouedraogo Teaching Hospital of Ouagadougou. Results: The average age of the patients was 31.7 years and the age groups most affected were those between 16 - 26 years. Our study population were mainly pupils and students with $40.5 \%$ of cases. Causes of trauma to the external genitalia were mainly highway accident with 19 cases $(45.2 \%$ of cases $) .85 .7 \%$ of patients presented on the day of the trauma. Scrotum and its contents were more exposed to trauma (30 cases) than penis (12 cases). Treatment was most often surgical $(78.6 \%)$. The postoperative course was uneventful in $75 \%$ of the cases of testicular trauma and $72.7 \%$ of the cases of penile trauma. Conclusion: External genitalia traumas affect young people. Complications can be important like erectile dysfunction. However, the prognosis is good if treatment is early.
\end{abstract}

\section{Keywords}

Male External Genitalia-Trauma-Emergency

\footnotetext{
${ }^{*}$ Corresponding author.
}

How to cite this paper: Zango, B., Kabore, F.A., Pare, A.K., Kirakoya, B., Yameogo, C.A.M.K.D., Ouattara, A. and Zare, C. (2015) Trauma to the Male External Genitalia: Epidemiology, Diagnosis and Therapeutic Aspects at Yalgado Ouedraogo Teaching Hospital of Ouagadougou. Open Journal of Urology, 5, 103-108. http://dx.doi.org/10.4236/oju.2015.57016 


\section{Introduction}

Trauma to the male external genitalia (TMEG) is defined as open or closed traumatic lesions caused by an external mechanical force on the penis, the scrotum and its contents [1]. It is a relatively infrequent trauma which affects young patients [2]. The TMEG is a real medico-surgical emergency. It can be easily diagnose. But the precise pathological diagnosis can sometimes be difficult and may require surgical exploration straight away [3] [4]. This work aimed at studying retrospectively the epidemiology, diagnosis and treatment of TMEG seen at the urology emergency department of Yalgado Ouedraogo Teaching Hospital.

\section{Materials and Method}

It is a retrospective study over a period of six and half years, from January $1^{\text {st }}, 2006$ to June $30^{\text {th }}$, 2012. It includes all the male patients admitted with trauma to the external genitalia confirmed by the clinical examinationin the urology emergency department of Yalgado Ouedraogo Teaching Hospital. The studied variables were the age, the profession, the zone of residence, the circumstance surrounding the trauma, the clinical examination findings, the treatment given and the outcome of the treatment. Statistical analysis was done using Epi info version 3.1 and SPSS 17.0. The variables were analyzed in terms of frequency and average. The study has been performed with the approval of a medical ethics committee.

\section{Results}

In six and half years, 109 cases of urogenital traumas (UGT) were recorded, among which 42 cases (38.5\%) were trauma to the male external genitalia. The annual incidence average was 6.5 cases per year. The average age of the patients was 31.7 years with range of 5 to 70 years. The age group of 16 to 26 years has the highest frequency (15 case) as shown in Figure 1. Pupils and students were the most vulnerable group with 17 cases (40.5\%) seen over the studied period. Most of the patients lived in urban areas 26 cases (62\%).

The average duration before presentation was of 1.4 day with a range of 1 to 5 days. Thirty six patients (85.7\%) presented on the day of the trauma.

The mechanism of injury to the scrotal sac and its contents was mainly direct trauma while traumas to the penis usually occurred during sexual intercourses (Table 1). The main cause of trauma to the male external genitalia was road traffic accidents with 19 cases (45.24\%) seen over the studied period as shown in Table 2.

Twenty seven patients have opened traumas (64.3\%), while 15 patients (35.7\%) have closed trauma.

The different types of injuries seen were shown on Table 3. For the traumas of the scrotum, the classification of the American Association for the Surgery of Trauma was used.

All the cases of open traumas of the external genitalia benefited from a surgical exploration in the emergency room, they also had tetanus toxoid booster doses. In the patients with closed trauma, three had ultrasonography of the external genitalia and only two patients had surgeries. In all, 35 patients had surgeries.

The operation time was less than 12 hours in 25 patients (71.4\%), between 12 and 24 hours in 6 patients (17.1\%) and after 24 hours in among 2 patients (5.7\%). Table 4 depicts distribution of various surgical procedures carried out on these patients.

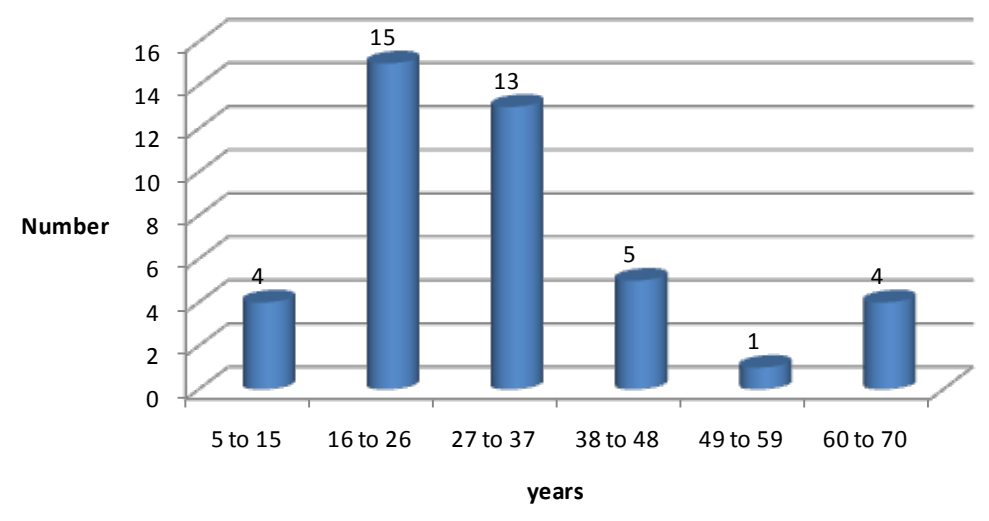

Figure 1. Distribution of patients according age group. 
Table 1. Distribution of patients according mechanism of trauma.

\begin{tabular}{lcc}
\hline \multicolumn{2}{c}{ Mechanism of trauma } & Number \\
& Sexual intercourses & 4 \\
& Animals/human bite & 3 \\
Penis & Direct shock & 2 \\
& Forced manipulation of the penis & 2 \\
Self mutilation & 1 \\
Scrotum and theirs & Direct shock \\
Contents & impalement & 22 \\
Total & & 8 \\
\hline
\end{tabular}

Table 2. Distribution of patients according etiology of trauma.

\begin{tabular}{ccc}
\hline Causes & Number & Percent (\%) \\
\hline Road traffic accidents & 19 & 45.24 \\
Domestic accident & 6 & 14.28 \\
Missteps of coitus & 4 & 9.53 \\
Encornement & 3 & 7.14 \\
Cold steel & 3 & 7.14 \\
masturbation & 2 & 4.76 \\
Work accident & 2 & 4.76 \\
Guns & 1 & 2.38 \\
Dog bite & 1 & 2.38 \\
Football & 1 & 2.38 \\
Total & 42 & 100 \\
\hline
\end{tabular}

Table 3. Distribution of patients according lesionel diagnosis of external genitalia of trauma.

\begin{tabular}{|c|c|c|}
\hline \multicolumn{2}{|c|}{ Lesionel type } & \multirow{2}{*}{$\begin{array}{c}\text { Numbe } \\
4\end{array}$} \\
\hline \multirow{5}{*}{ Penis } & simpleruptureof corpora cavernosa & \\
\hline & $\begin{array}{l}\text { cavernosal and/or spongiosa } \\
\text { corporeal rupture - urethral lesion }\end{array}$ & 2 \\
\hline & Sectionof erectil corporeal-urethral lesion & 3 \\
\hline & Partial penectomy & 1 \\
\hline & Pull the foreskin & 1 \\
\hline \multirow{6}{*}{ Scrotum and their contents } & Contusion of penis & 1 \\
\hline & Grade I AAST & 24 \\
\hline & Grade II AAST & 2 \\
\hline & Grade III AAST & 1 \\
\hline & Grade IV AAST & 1 \\
\hline & Grade V AAST & 2 \\
\hline Total & & 42 \\
\hline
\end{tabular}


Table 4. Distribution according various modalities of management of external genitalia trauma.

\begin{tabular}{ccc}
\hline Therapeutic modalities & Number & Percent (\%) \\
\hline Hemostasis & 24 & $57.1 \%$ \\
Evacuation of hematoma-suturing corpora cavernosa & 8 & $19.1 \%$ \\
Penectomy regularisation & 1 & $2.4 \%$ \\
Uretrorraphyend to end & 5 & $11.9 \%$ \\
Circumcision & 1 & $2.4 \%$ \\
Orchiectomy & 3 & $7.1 \%$ \\
Total & 42 & $100 \%$ \\
\hline
\end{tabular}

The average duration of hospital stay was four days with a range of 1 to 25 days. The recovery following surgical treatment for penile trauma was good and without complication in eight cases and mild complications in three cases which included two cases of painful erection and a case of erectile dysfunction. A patient with what seem to be simple penile contusion developed acute urine retention secondary to an ignored urethral lesion. The medium-term evaluation for all the patients was revealed complication in nine patients. Seven patients have residual pain while two have erectile dysfunction. There were no case of death in our study.

\section{Discussion}

Trauma to male external genitalia is not an uncommon urological emergency. It account for $38.5 \%$ of all the urogenital trauma in our study. Moby Mpah et al. [5] in Cameroon and Fall et al. [6] in Dakar found even higher rates of $51.5 \%$ and $86.9 \%$ respectively. This showed that these traumas deserve to be studied.

The most vulnerable population are those driving motorbike or bicycle and those that are sexually very active. These are young populace particular the pupils and students. Thus age group of 16 to 26 years were more vulnerable, we noted an average age of 31.7 years, this is similar to reportby Shaul [7], and Kleinclauss [4] who reported average age of their patient to 28 years and 29 years. Road traffic accidents account for $55.2 \%$ of the cases. Similar result (89\%) was reported by Barthelemy [8]. The mechanisms of injury is generally direct trauma to the genital organs by hard part of the vehicle (e.g. bicycle or motorcycle handlebars) [4]. Penile traumas usually followed forceful coitus ( 4 cases) and masturbation (2 cases). This is in conformity with data in the literature [9]-[14]. A rare situation is self-mutilation as reported by Moufid K. et al. [15] (three cases) and by Kaboré et al. [16] (one case). To avoid the repetition, the surgical treatment must be framed by a psychiatric assumption of responsibility.

As found in the literature [3] [17] [18], the average duration before presentation range from few hours to a few days. Most patients presents on the same day of trauma. This early presentation could be in an attempt to avoid possibility of penile deformity and erectile dysfunction. Most of the cases in our study have open trauma (64.3\%), this is similar to report by Hodonou et al. (60\%) [3]. But in some European studies, closed trauma are commoner. Kleinclauss noted $84 \%$ of their cases to be closed trauma [4]. This could be due to under reporting of close genital trauma. Most patients in the sub-Saharan African may not present to hospital unless if there is obvious open wound. They may resort to self-medication or traditional medicine in the event of closed trauma. The scrotum and its contents is more prone to injury than the penis (30 cases against 12). The same report was made by Hodonou et al. [3] and Shaul [7]. The larger volume of the scrotum compared to penis make at higher risk of trauma. Testicular injury following trauma to the scrotum is rare. This may be due to the fact that testicle are mobile and they are protected by tunica albuginea. This may the reason why only three cases of testicle injuries were recorded out of 30 cases of trauma to the scrotum. The most common grade of scrotal injury seen in our study was grade I of the AAST with 24 cases recorded. This is similar to report by Hodonou et al., and Kleinclauss [3] [4]. In patient with penile trauma, the most common pathology seen was rupture of the cavernous body as also reported in the literature [12] [19]. The mobility of the penis makes it less vulnerable to injury. Injury to the penis rather occurs following mishandling of an erect penis or forceful coitus. Mianne et al. [20], Fall et al. [6] report that the surgical treatment were systematic in the open traumas and in the trauma of penis. The surgical treatment in the closed traumas of the scrotum was indicated by ultrasonography.

We realized in three cases that ultrasonography has enabled us to avoid operating in them. However, ultraso- 
nography is not alternative to clinical judgement. Moreover, Kleinclauss [4] after surgical exploration, realized that five out of 12 cases of tunica albuginea rupture were missed on ultrasonography. Mullhaul et al. [21] also found that three out of six cases of tunica albuginea rupture were missed on ultrasonography. Hence, Altarac [22] and Cass [23] suggested that any trauma to the scrotum with large hematoceles must be explored surgically as soon as possible. Complications of penile trauma may include painful erection (36.4\%) or erectile dysfunction (9.1\%). Benchekroun noted $22 \%$ of painful erection. In patient with scrotal trauma, we noted complications similar the one reported by Kleinclauss and Hammadi [4] [18]. This includes testicular pain and erectile dysfunction. The erectile dysfunction is often psychogenic but sometimes, there may be organic component such as post-traumatic testicular atrophy or bilateral orchidectomy. The one month follow up in our study is not enough to conclude on the possible complications and outcome of treatment.

\section{Conclusion}

Trauma to the male external genitalia is mostly seen young patient in Burkina Faso. The most common cause of Trauma to the external genitalia is road traffic accidents. Though the diagnosis is easy to make and it is mainly clinical, there may be need to do some complementary investigation such as ultrasonography. Occasionally, final diagnosis could only be made after surgical exploration. Surgical exploration must be done in patient with clinical suspicion of rupture of the tunica albuginea.

\section{References}

[1] Sherif, A.E., Renaldo, G.G. and McAninch, J.W. (1993) Genital Self-Mutilation. Journal of Urology, 150, $1143-1146$.

[2] Benchekroun, A., Iken, A., Kasmaoui, E., et al. (2001) Scrotal Trauma. A Report of 40 Cases. Annales d'Urologie, 35, 349-352. http://dx.doi.org/10.1016/S0003-4401(01)00058-4

[3] Hodonou, R.K., Diallo, A. and Akpo, E.C. (1997) Trauma to the Male External Genitalia: A Report of 20 Cases. Annales d'Urologie, 31, 318-321.

[4] Kleinclauss, F., Martin, M., Chabannes, E., Bernardini, S., Dellanegra, E. and Bittard, H. (2001) Testicular Traumas: A Report of 57 Cases. Progrès en Urologie, 11, 486-491.

[5] Moby Mpah, E.H., Fouda, P.J., Sala-Beyeme, T., Eboumbou Moukoko, E.C., Njifou Njimah, A., Tsiagadigui, J.-G., Berthe, H.J.G., Mekeme Mekeme, J. and Angwafo III, F. (2012) Andrological Emergencies in Urban Areas in Cameroun. Clinical and Therapeutic Aspects. Andrologie, 22, 223-226.

[6] Fall, B., Diao, B., Fall, P.A., Diallo, Y., Sow, Y., Ondongo, A.A.M., Diagana, M., Ndoye, A.K., Ba, M. and Diagne, B.A. (2008) Urological Emergencies at Dakar University Teaching Hospital. Epidemiological, Clinical and Therapeutic Features. Progrès en Urologie, 18, 650-653. http://dx.doi.org/10.1016/j.purol.2008.04.004

[7] Shaul, D.B., Xie, H.W., Diaz, J.F., Mahnovski, V. and Hardy, B.E. (1997) Surgical Treatment of Testicular Trauma: Effects on Fertile and Testicular Histology. Journal of Pediatric Surgery, 32, 84-87. http://dx.doi.org/10.1016/S0022-3468(97)90101-9

[8] Barthelemy, Y., Delmas, V., Villers, A., Baron, J.C., SIBERT, A. and Boccon-Gibod, L. (1992) Scrotal Trauma. Report of 33 Cases. Progrès en Urologie, 2, 628-634.

[9] Benchekroun, A., Abakka, I. and Lakrissa, A. (1986) Fracture of the Corpus Cavernosa. About 22 Cases. Journal of Urology, 92, 2915.

[10] Hinev, A. (2000) Fracture of the Penis: Treatment and Complications. Acta Medica Okayama, 54, 211-216.

[11] Mansi, M.K., Emran, M., EL-Mahrouky, A. and EL-Mateet, M.S. (1993) Experience with Penile Fractures in Egypt: Long-Term Results of Immediate Surgical Repair. The Journal of Trauma, 35, 67-70. http://dx.doi.org/10.1097/00005373-199307000-00011

[12] Boujnah, H. and Rakam, S. (1990) Fracture of the Corpus Cavernosa: About of 67 Cases. Annalesd' Urologie, 24, 313315.

[13] Asgari, M.A., Hosseini, S.Y., Safarinejad, M.R., Samadzade, B. and Bardideh, A.R. (1996) Penile Fractures: Evaluation, Therapeutic Approaches and Long Term Results. The Journal of Urology, 15, 148-149. http://dx.doi.org/10.1097/00005392-199601000-00057

[14] Zargooshi, J. (2000) Penile Fracture in Kermanshah, Iran: Report of 172 Cases. The Journal of Urology, 164, 364-366. http://dx.doi.org/10.1016/S0022-5347(05)67361-2

[15] Moufid, K., Joual, A., Debbagh, A., Bennani, S. and EL-Mrini, M. (2004) Genital Self-Mutilation: Report of 3 Cases. Progrès en Urologie, 14, 540-543. 
[16] Kaboré, A., et al. (2008) Recurrent Self-Mutilation of the Penis in a Context of Schizophrenia: About One Case. Andrologie, 18, 224-226.

[17] Bennani, S., EL Mrini, M., Meziane, F. and Benjelloun, S. (1992) Traumatic Rupture of the Corpus Cavernosa: Analysis of 25 Cases and Literature Review. Annales d'Urologie, 26, 355.

[18] Hammadi, F., et al. (2007) Blunt Scrotal Trauma, Management Strategy. Andrologie, 17, 42-48.

[19] Benjelloun, M., Rabii, R., Bennani, S., Querfani, B. and Joual, A. (2003) Fracture of the Corpus Cavernosa. A Report of 123 Cases. African Journal of Urology, 9, 48-52.

[20] Mianne, D., Guillotreau, J. and Sergent, H. (1997) Perineal Injuries in Wartime. Annales d'Urologie, 31, 303-308.

[21] Mulhaull, J.P., Gabram, S.G. and Jacobs, L.M. (1995) Emergency Management of Blunt Testicular Trauma. Academic Emergency Medicine, 2, 639-643. http://dx.doi.org/10.1111/j.1553-2712.1995.tb03604.x

[22] Altarac, S. (1994) Management of 53 Cases of Testicular Trauma. European Urology, 25, 119-123.

[23] Cass, A.S. and Luxemberg, M. (1988) Value of Early Operation in Blunt Testicular Contusion with Hematocele. The Journal of Urology, 139, 746-747. 